\title{
Probability in gene expression
}

\section{To the Editor:}

As a medical geneticist, I always face the difficulty of explaining variable penetrance and expressivity in a genetic disorder to my patients. This means that the same disease causing mutation may produce significantly variable manifestations of the disorder (from asymptomatic to severely affected) even in members of the same family as well as in monozygotic twins. Indeed, elegant phrases, such as stochastic or variable gene expression/regulation as well as noise in gene regulation may be found in the literature that may explain this phenomenon. ${ }^{1,2}$ The source of these genetic fluctuations can be extrinsic (environmental) and/or intrinsic (arising in the cells or the organism). Complicated equations are utilized to describe this probability in gene expression. Nonetheless, the conclusion is discouraging during genetic counseling since, for instance, an asymptomatic carrier of an autosomal dominant pathogenic mutation may have a 50\% chance of transmitting a disorder with unpredictable severity. One has to admit that despite of the tremendous advancement in unraveling the genetic basis of human diseases; probability and chance complicate our knowledge and significantly affect our capability for prognosis. Consequently, while there is much wisdom in Albert Einstein's comment that "God does not play dice with the universe," it is humbling to experience our limitations in understating the stochastic elements in nature. Despite his earlier comment, Einstein himself beautifully phrased this wonder later in his life: "The most beautiful and deepest experience a man can have is the sense of the mysterious. It is the under- 
lying principle of religion as well as all serious endeavors in art and science. He who never had this experience seems to me, if not dead, then at least blind. To sense that behind anything that can be experienced there is something that our mind cannot grasp and whose beauty and sublimity reaches us only indirectly and as a feeble reflection, this is religiousness. In this sense I am religious. To me it suffices to wonder at these secrets and to attempt humbly to grasp with my mind a mere image of the lofty structure of all that is there." ${ }^{3}$ How true this is for the medical genetics of our era.
Richard Kellermayer, MD, PhD

Department of Medical Genetics and Child Development

University of Pécs, Hungary

\section{References}

1. Raser JM, O'Shea EK. Noise in gene expression: origins, consequences, and control. Science 2005;309:2010-2013.

2. Bratsun D, Volfson D, Tsimring LS, Hasty J. Delay-induced stochastic oscillations in gene regulation. Proc Natl Acad Sci U S A 2005;102:14593-14598.

3. Torrance T. Einstein and God. Center of Theological Inquiry, Princeton (NJ), 20022004. Available at: http://www.ctinquiry.org/publications/reflections_volume_1/ torrance.htm. Accessed February 21, 2006. 